\title{
ACTIVIDADES CREATIVAS Y DESARROLLO EN LAS PEQUEÑAS CIUDADES: TERUEL COMO EJEMPLO
}

\author{
Ana Isabel Escalona Orcao ${ }^{1}$, Luis Antonio Sáez Pérez ${ }^{2}$, Luisa María Frutos Mejías ${ }^{1}$ y Blanca Loscertales Palomar $^{1}$ \\ ${ }^{1}$ Departamento de Geografía y Ordenación del Territorio, Universidad de Zaragoza \\ ${ }^{2}$ Departamento de Estructura e Historia Económica y Economía Pública, Universidad de Zaragoza
}

\section{RESUMEN}

Una de las razones que explican la búsqueda de nuevas oportunidades de crecimiento en las pequeñas ciudades de las áreas menos avanzadas de Europa es la persistencia de fuertes desequilibrios territoriales. El aprovechamiento de su patrimonio cultural favorece el desarrollo de estrategias basadas en el talento local y adaptadas a la personalidad del territorio. El artículo se centra en la ciudad de Teruel y estudia cómo la tradición de los amantes y de las bodas de Isabel Segura, que se recrea anualmente desde 1997, ha contribuido a la generación de actividades creativas en la ciudad y su entorno próximo. El análisis realizado nos ha permitido conocer y evaluar los vínculos existentes entre sus componentes y las externalidades positivas e impactos socioeconómicos generados. El caso estudiado tiene un interés teórico añadido, porque permite reconstruir el desarrollo, estructura interna e impacto territorial de un potencial cluster creativo. El artículo presenta la zona de estudio, realiza la revisión de los conceptos de cluster y de actividades creativas y se centra después en la recreación de Las Bodas de Isabel de Segura considerando su génesis, evolución, estructura, sinergias funcionales e impacto territorial en la estructura productiva y en la sociedad local.

Palabras clave: Actividades creativas, patrimonio cultural, cluster, desarrollo local,

\section{ABSTRACT}

\section{Creative activities and development in small towns. The example of Teruel}

One of the reasons for searching new growth opportunities in the small cities of the less developed areas in Europe is the persistence of strong regional imbalances. Cultural heritage provides a good ressource because it encourages the development of activities based in local talent and adapted to the territory. The article focuses on the city of Teruel and shows how the Middle Age tradition of the weddings of Isabel Segura, which is recreated annually since 1997, has contributed to the generation of various creative activities in the city and its immediate environment. The paper begins introducing the study area. The theoretical chapter reviews the concepts of cluster and creative activities. We then proceed to the analytical content considering the genesis of the recreation, its evolution, functional structure and synergies, in order to evaluate if the activities involved constitute a creative cluster and assess the positive externalities and socioeconomic and spatial impacts generated. The conclusion summarises the relevant issues and includes suggestions for further research

Keywords: Creative activities, heritage, cluster, local development

\section{INTRODUCCIÓN ${ }^{1}$}

Las áreas rurales y muchas de las pequeñas ciudades de España y de otros países de Europa presentan una situación de menos desarrollo respecto de las grandes ciudades y metrópolis. Esta afirmación es muy

Contacto: Ana Isabel Escalona Orcao: aescalon@unizar.es; Luis Antonio Sáez Pérez: lasaez@unizar.es; Luisa María Frutos Mejías: lmfrutos@unizar.es; Blanca Loscertales Palomar: bloscer@unizar.es

1 Este artículo se enmarca en el proyecto de investigación "Los clusters de actividades creativas en las áreas semiurbanas y rurales españolas: Factores e impacto en el desarrollo territorial", que resultó seleccionado en la convocatoria 2012 del Proyectos de Investigación no Orientada del Ministerio de Economía y Competitividad. Contiene algunos resultados presentados en una versión preliminar a las XXIX Jornadas de Ciencia Regional (Oviedo, 2013), sin que hayan sido publicados. 
clara en el territorio español, con un marcado desequilibrio demográfico y económico entre las zonas costeras y las del interior, excepto Madrid, que, si bien tiene raíces históricas anteriores, se consagra definitivamente a partir del cambio estructural, económico y social, iniciado en la segunda mitad del siglo pasado. La provincia de Teruel es muy representativa: su capital con 35.961 habitantes en 2013 es la de menor población de España; además, los 143.728 habitantes de la provincia representan solo un $44 \%$ de los registrados en 1900. La densidad media es de las más bajas de Europa, con 9,4 hab/ $/ \mathrm{km}^{2}$ en la provincia, e incluso desciende hasta los $4 \mathrm{hab} / \mathrm{km}^{2}$ en el entorno de la capital, lo que permite calificar de desierto demográfico a una amplia parte del territorio. Las políticas europeas han tenido en cuenta estos factores y se han puesto en marcha iniciativas, como la LEADER u otras, que han supuesto subvenciones públicas sensiblemente superiores a la de territorios equivalentes (Art. 87.3.c del Tratado CE). De hecho la provincia de Teruel ha sido beneficiaria de una financiación especial desde 1993, "el Fondo de Inversiones de Teruel", con la participación del gobierno español y aragonés. Pero estas medidas no han dado el fruto esperado de modo que ni la provincia ni su capital han dinamizado suficientemente su tejido económico.

Ante esta situación, los expertos y los gestores públicos han buscado nuevas vías para activar la economía local y ayudar en la consecución de un desarrollo endógeno, basado en recursos materiales e inmateriales de carácter histórico o cultural y ligados a la personalidad del territorio y de sus gentes. Las líneas maestras de las políticas europeas de desarrollo local para el periodo 2014-2020, recogen este tipo de actuaciones que, por un lado, favorecen la iniciativa del emprendedor a través de la financiación y asesoramiento específico, y por otro, pretenden reforzar las peculiaridades territoriales y la identidad de estos espacios, suscitando, de este modo, el aprecio y arraigo de la población. Este es el caso de las actividades creativas, como ha quedado patente en diversas investigaciones recientes. La Unión Europea considera que están en condiciones de sustentar un desarrollo inteligente, sostenible e inclusivo de todas las regiones y ciudades europeas y de extender dicho desarrollo al conjunto de la economía (Comisión Europea, 2012: 3). Teruel y su entorno parecen espacios apropiados para estas actividades que combinan lo creativo y lo local, ya que cuenta con un amplio patrimonio natural y cultural y este último, tanto material como inmaterial, es susceptible de convertirse en un activo explícito de ese tipo de actividades. Se cuenta además con experiencia en su puesta en valor desde el último tercio del siglo pasado, ya que han ido surgiendo iniciativas muy variadas a las que se suman otras, como la fiesta de Las Bodas de Isabel de Segura objeto de análisis en este artículo.

Existen numerosos estudios sobre las actividades creativas en las grandes ciudades y regiones metropolitanas españolas (Méndez et al, 2012; Lazeretti, Boix y Capone, 2008). Por el contrario, las pequeñas ciudades apenas han sido objeto de estudios específicos desde esta perspectiva. Cabe añadir, además, que los modelos teóricos de referencia como el concepto de cluster -manejado en esta investigación- no se han inspirado en ellas para construir sus marcos analíticos. En este contexto, contrastar la validez del concepto "cluster de actividades creativas" como marco de estudio para la ciudad de Teruel, ha constituido un importante reto. Los resultados obtenidos verifican la pertinencia del marco adoptado y permiten afirmar que Teruel es un claro ejemplo de actividades creativas emergentes aunque sus interrelaciones sólo denoten un estadio inicial en su configuración como cluster. Hemos observado también que el conocimiento y refuerzo de las peculiaridades del territorio y el aprecio creciente de la población por algo que percibe como propio, han favorecido que las actividades perduren y contribuyan al aumento del capital social en la capital y en su área de influencia. Por todo ello el caso estudiado proporciona elementos que confirman las expectativas suscitadas por las actividades creativas como herramientas de las políticas de desarrollo local y regional.

\section{LA TRADICIÓN Y EL PATRIMONIO COMO RECURSOS PARA EL DESARROLLO LOCAL. ORÍGENES DE LA CELEBRACIÓN DE LAS BODAS DE ISABEL DE SEGURA}

Teruel y su provincia cuentan con un importante patrimonio histórico y cultural. La Organización de las Naciones Unidas para la Educación, la Ciencia y la Cultura, UNESCO, declaró en 1986 al mudéjar turolense como Patrimonio de la Humanidad, dando con ello un fuerte impulso al turismo cultural. Por otra parte, siempre han existido asociaciones y redes de carácter cultural y social, pero su alcance era limitado, ya que quedaba circunscrito a especialistas y a los grupos más participativos de cada localidad, normalmente minoritarios y sin trascendencia económica y social relevantes. Solo las festividades tradicionales lograban aglutinar al conjunto de la comunidad, pero con una finalidad lúdica y reducida a la esfera más personal de relaciones, concentrándose en unos pocos días. Puede afirmarse, por tanto, que, 
aunque Teruel contaba con un amplio capital histórico, antropológico, arquitectónico y medioambiental, no se le había sacado partido de forma plena, ni siquiera dentro de los procesos pasados de reestructuración del medio rural, que tienden a valorar estos recursos e incluso a introducirlos en los mercados residenciales, turísticos y de ocio (Hoggart y Paniagua, 2001).

La iniciativa de celebrar Las Bodas de Isabel de Segura representa un importante cambio. La leyenda de los Amantes de Teruel, que da origen a la fiesta, relata una trágica historia de amor y de muerte que tuvo lugar en el siglo XIII entre Isabel de Segura y Juan (o Diego) Martínez de Marcilla o Marsilla. Como otras leyendas, forma parte del patrimonio inmaterial, de la tradición y del imaginario colectivo español y ha sido objeto de atención de literatos, músicos y pintores desde el Siglo de Oro hasta el Romanticismo, destacando, en esta época, la obra del escritor Juan Eugenio Hartzenbusch. Estos antecedentes y la identificación popular con la leyenda, impulsaron a la Asociación de Empresarias de Teruel a llevar a cabo su recreación teatralizada, solicitando una subvención de la Unión Europea para ponerla en marcha con el apoyo de la Cámara de Comercio de Teruel. Aquí se encuentra el germen de lo que iba a llegar a ser un verdadero fenómeno sociológico a partir de la primera recreación histórica, que tuvo lugar en 1997, durante un fin de semana de febrero próximo al día de san Valentín, con un notable éxito, aunque con una participación modesta de la población. Desde el inicio se contó con la colaboración de diversas personas de la ciudad, que asumieron la organización y gestión de diversos aspectos de la celebración, a la vez que el Ayuntamiento de la ciudad prestó el apoyo institucional desde el inicio, ayudando a su financiación.

La fiesta fue consolidándose en sucesivas ediciones. Desde 2001 Las Bodas forman parte de las federaciones española y europea de Fiestas y Recreaciones históricas y en 2005 se crea la Fundación Bodas de Isabel Segura, patrocinada por el Ayuntamiento, la confederación provincial de empresarios y una entidad bancaria local. La edición de 2010 incorpora por vez primera una segunda actuación, La partida de Diego, celebrada a principios de octubre y que en su edición de 2013 vino acompañada de la organización del I Congreso Internacional de Fiestas y Recreaciones Históricas. Ya en 2007 esta fiesta fue declarada de Interés Turístico Regional y actualmente se está tramitando la solicitud de su declaración como fiesta de Interés Turístico Nacional.

\section{LOS CLUSTERS DE ACTIVIDADES CREATIVAS Y SU ESTUDIO EN LAS PEQUEÑAS CIUDADES ESPAÑOLAS. FUNDAMENTOS, EVIDENCIAS E IMPLICACIONES ANALÍTICAS}

El análisis de las actividades creativas como herramientas de desarrollo en las pequeñas ciudades como Teruel, requiere su definición e identificación previas. Uno de sus rasgos distintivos es la generación de "...productos tangibles o servicios intangibles -intelectuales o artísticos- con contenido creativo, valor económico y objetivos de mercado" (United Nations, 2010: 7). A ello se añade que tienen su origen en la aplicación del talento individual con fines empresariales y que se les presupone un alto potencial para la promoción del desarrollo territorial (Bakhshi, Freeman y Higgs, 2013). La tabla 1 sintetiza sus distintos ámbitos e identifica las actividades de la Clasificación Nacional de Actividades Económicas (CNAE-2009) y las ocupaciones de la Clasificación Nacional de Ocupaciones (CON-2011) que consideramos que se ajustan con los rasgos definitorios aportados.

Cuadro 1. Caracterización e identificación de las actividades creativas

\begin{tabular}{|c|c|c|}
\hline ÁMBITO & SECTOR & Actividad (CNAE-09)/Ocupación (CON-2011) \\
\hline \multirow{2}{*}{ PATRIMONIO } & Artesanía & $\begin{array}{l}\text { 321. Fabricación de artículos de joyería, bisutería y similares } \\
\text { 761. Mecánicos de precisión en metales, ceramistas, vidrieros y artesanos }{ }^{2}\end{array}$ \\
\hline & $\begin{array}{l}\text { Gestión de espacios de interés } \\
\text { cultural }\end{array}$ & $\begin{array}{l}\text { 910. Actividades de bibliotecas, archivos, museos y otras actividades } \\
\text { culturales }\end{array}$ \\
\hline \multirow{2}{*}{ ARTES } & \multirow{2}{*}{$\begin{array}{l}\text { Artes escénicas (música, teatro, } \\
\text { circo, danza, ópera, títeres) }\end{array}$} & 900. Actividades de creación artísticas y espectáculos \\
\hline & & 742. Actividades de fotografía \\
\hline
\end{tabular}

2 Categoría de la Clasificación Nacional de Ocupaciones 2011 que incluye las siguientes ocupaciones artesanales: Relojeros y mecánicos de instrumentos de precisión; Lutieres y similares; afinadores de instrumentos musicales; Joyeros, orfebres y plateros; Trabajadores de la cerámica, alfareros y afines; Sopladores, modeladores, laminadores, cortadores y pulidores de vidrio; Rotulistas, grabadores de vidrio, pintores decorativos de artículos diversos; Artesanos en madera y materiales similares; cesteros, bruceros y trabajadores afines; Artesanos en tejidos, cueros y materiales similares, preparadores de fibra y tejedores con telares artesanos o de tejidos de punto y afines; Artesanos no clasificados bajo otros epígrafes 


\begin{tabular}{|c|c|c|}
\hline \multirow{6}{*}{ COMUNICACIÓN } & $\begin{array}{l}\text { Publicaciones y medios } \\
\text { impresos }\end{array}$ & 581. Edición de libros y otras actividades editoriales \\
\hline & \multirow{5}{*}{$\begin{array}{l}\text { Audiovisuales, producción } \\
\text { de radio y televisión }\end{array}$} & 182. Reproducción de soportes grabados \\
\hline & & 591. Actividades cinematográficas, de video y de programas de televisión \\
\hline & & 592. Actividades de grabación de sonido y edición musical \\
\hline & & 601. Actividades de radiodifusión \\
\hline & & 602. Actividades de programación y edición de televisión \\
\hline \multirow{7}{*}{$\begin{array}{l}\text { CREACIONES } \\
\text { FUNCIONALES }\end{array}$} & Diseño & 741. Actividades de diseño especializado \\
\hline & Arquitectura & $\begin{array}{l}\text { 711. Servicios técnicos de arquitectura e ingeniería y otras actividades } \\
\text { relacionadas con el asesoramiento técnico }\end{array}$ \\
\hline & \multirow{3}{*}{ Publicidad } & 731. Publicidad \\
\hline & & 732. Estudios de mercado y realización de encuestas de opinión pública \\
\hline & & 702. Actividades de consultoría de gestión empresarial \\
\hline & \multirow{2}{*}{$\begin{array}{l}\text { Informática, juegos y } \\
\text { publicaciones electrónicas }\end{array}$} & 582. Edición de programas informáticos \\
\hline & & $\begin{array}{l}\text { 620. Programación, consultoría y otras actividades relacionadas con la } \\
\text { informática }\end{array}$ \\
\hline
\end{tabular}

Fuente: Elaboración propia.

Estudios recientes llevados a cabo en España y en otros países europeos sobre el significado y localización de estas actividades, han dejado patente su concentración en las grandes áreas urbanas y un peso económico, en términos de producción y empleo, por debajo de las expectativas (Sánchez, Méndez y Arellano, 2014). Ello parece dejar fuera del ámbito de desarrollo de estas actividades a las pequeñas ciudades y las áreas rurales. Sin embargo investigaciones del equipo al que pertenecen los autores de este trabajo han evidenciado una presencia significativa de estas actividades en las pequeñas ciudades y áreas rurales españolas, como se refeja en el siguiente mapa. ${ }^{3}$

Figura 1. Pequeñas ciudades y municipios rurales de Aragón y Castilla la Mancha con presencia de actividades creativas



La hipótesis de partida de este trabajo es que el impacto potencial de las actividades creativas en el desarrollo de las respectivas localidades aumenta si forman parte de clusters. Cabe recordar, en primer

3 En el marco de la investigación se consideran pequeñas ciudades las que tienen 75.000 habitantes o menos. 
lugar, que el concepto de cluster se consolidó en los análisis académicos a finales del siglo pasado, cuando Porter (1998) redefinió las externalidades intra e inter sectoriales que aumentan la productividad empresarial. Se asume que los clusters -como concentraciones geográficas de empresas interrelacionadas, proveedores especializados y empresas e instituciones de sectores afines- favorecen la aparición y difusión de innovaciones, conocimiento y crecimiento; y que ello tiene para sus integrantes y para el entorno múltiples efectos positivos (Rodríguez-Pose and Comptour, 2012). A este respecto Bathelt et al (2004) recuperan el concepto de buzz, traducible por "zumbido" o "rumor", al que Storper y Venables (2002) atribuían los procesos de generación y difusión de conocimiento. Los últimos autores citados resaltan la importancia de un medio propicio para la información y la comunicación que surge, a su vez, de los contactos directos entre personas y empresas que trabajan en actividades semejantes y coinciden en un mismo espacio. Las fuentes externas de conocimiento que conectan al cluster con el resto del mundo son también muy importantes. Todo ello facilita la circulación de informaciones específicas y permanentemente actualizadas entre los componentes del cluster; se inducen aprendizajes espontáneos o sistematizados; aparece una percepción semejante de los nuevos conocimientos y tecnologías y se favorece la existencia de hábitos y tradiciones, lo que facilita que se puedan establecer convenciones y acuerdos institucionales en el cluster (Bathel et al, 2004: 38; Lundmark y Petterson, 2012).

Estos resultados plantean cuestiones de gran interés sobre los factores explicativos de esas dinámicas: por qué aparecen, qué tipo de actividades creativas predominan, cuáles son sus trayectorias, si los potenciales clusters pueden superar las restricciones geográficas convencionales o qué estrategias de desarrollo regional suscitan (v. cuadro 2).

Cuadro 2. Cuestiones de interés para el análisis de un cluster de actividades creativas en pequeñas ciudades y áreas rurales

\begin{tabular}{|c|c|}
\hline $\begin{array}{l}\text { Aspecto } \\
\text { al que se refieren }\end{array}$ & Cuestiones que deben ser objeto de análisis \\
\hline \multirow{4}{*}{$\begin{array}{l}\text { Desarrollo de la } \\
\text { iniciativa en un } \\
\text { contexto específico }\end{array}$} & $\begin{array}{l}\text { Presencia de agentes cualificados que realizan una función de liderazgo y de apoyo para la puesta } \\
\text { en marcha del cluster }\end{array}$ \\
\hline & $\begin{array}{l}\text { Creación de una organización que coordine la gestión e interactúe con todos los participantes en } \\
\text { la iniciativa }\end{array}$ \\
\hline & $\begin{array}{l}\text { Existencia de mecanismos para detectar y evitar actuaciones que puedan desvirtuar la naturaleza } \\
\text { de la iniciativa }\end{array}$ \\
\hline & Apoyo de fuentes de financiación diversificadas \\
\hline \multirow{6}{*}{$\begin{array}{l}\text { Relaciones entre los } \\
\text { integrantes del cluster }\end{array}$} & $\begin{array}{l}\text { Formación de redes de cooperación entre los participantes (empresas, instituciones, actores no } \\
\text { económicos u otros }\end{array}$ \\
\hline & $\begin{array}{l}\text { Unidad en la percepción de la iniciativa y presencia de objetivos claros compartidos por todos los } \\
\text { participantes }\end{array}$ \\
\hline & Existencia de mecanismos participativos para la toma de decisiones \\
\hline & Colaboración efectiva entre los sectores público y privado \\
\hline & Buena relación entre los integrantes, con independencia de su posible cooperación o competencia \\
\hline & Masa crítica: número suficiente de participantes y calidad de las actividades y servicios ofrecidos \\
\hline \multirow{5}{*}{ Impacto local } & Creación de una marca que permita su identificación con vistas a la difusión de la iniciativa \\
\hline & $\begin{array}{l}\text { Creación de reglamentos sobre la propiedad intelectual y la calidad de las actividades y productos } \\
\text { ofrecidos }\end{array}$ \\
\hline & Desarrollo del capital social \\
\hline & Impulso a la identidad local \\
\hline & Difusión en el entorno \\
\hline
\end{tabular}

Fuente: Adaptado a partir de Cinti, 2008. Elaboración propia

La investigación planteada está vinculada a un proyecto más amplio pero este artículo recoge solo los resultados de la parte de la investigación y aporta los testimonios de una selección de entrevistas semiestructuradas realizadas a agentes clave en el desarrollo de la fiesta. 


\section{LAS BODAS DE ISABEL DE SEGURA COMO EPICENTRO DE UN POSIBLE CLUSTER DE ACTIVIDADES CREATIVAS EN TERUEL. CONTEXTO, EVOLUCIÓN, ESTRUCTURA E IMPACTO.}

Esta parte del artículo se inicia con una breve descripción del perfil de las actividades creativas en Teruel. A continuación se centra en el modelo aplicado en la evolución de Las Bodas de Isabel de Segura, ya que difiere e incorpora algunas particularidades respecto de los modelos teóricos. Seguidamente se exponen y comentan los resultados de las entrevistas mantenidas con diferentes agentes cualificados y previamente seleccionados por su relación con cuestiones como la gobernanza del cluster, las interrelaciones detectadas y su difusión en el territorio.

\subsection{Contexto y evolución de la celebración}

La ciudad de Teruel ya destacaba en el año 2001 por la importancia relativa de sus actividades creativas, máxime teniendo en cuenta que el promedio observado era superior al de otras áreas rurales y al de las pequeñas ciudades españolas de menos de 70.000 habitantes. Contaban además con una mayor diversificación, aunque sobresalían claramente las actividades relacionadas con el patrimonio y las creaciones funcionales (cuadro 3).

Cuadro 3. Las actividades creativas en Teruel

\begin{tabular}{|c|c|c|c|c|c|c|c|c|}
\hline \multirow{2}{*}{ Ámbito espacial } & \multicolumn{9}{c|}{ Tipo de actividad creativa (n ocupados; \%) } \\
\cline { 2 - 11 } & \multicolumn{2}{|c|}{ Patrimonio } & \multicolumn{2}{|c|}{ Artes } & \multicolumn{2}{c|}{ Comunicación } & \multicolumn{2}{c|}{$\begin{array}{c}\text { Creaciones funcio- } \\
\text { nales }\end{array}$} \\
\hline Teruel & 194 & 40,9 & 31 & 6,5 & 67 & 14,1 & 182 & 38,4 \\
\hline $\begin{array}{c}\text { Áreas rurales y pequeñas } \\
\text { ciudades españolas }\end{array}$ & 9.133 & 50,2 & 8.203 & 4,8 & 17.456 & 10,1 & 56.844 & 32,9 \\
\hline España & 209.021 & 27,6 & 4.254 & 5,3 & 128.263 & 16,9 & 380.818 & 50,2 \\
\hline
\end{tabular}

Fuente: Escalona et al (en prensa)

Estas actividades siguen teniendo una gran importancia como lo demuestran las estadísticas de afiliados a la Seguridad Social. En el año 2011 existían en Teruel un total de 548 afiliados sin contar los artesanos (censados en otras fuentes). Es significativo que más de la mitad de los mismos corresponden a sectores integrados en la categoría de creaciones funcionales, si bien el que se trate de servicios cualificados que contribuyen como parte del proceso productivo de un conjunto muy amplio de actividades productivas, entre otras la construcción con su burbuja experimentada durante el período de estudio, puede ser una causa explicativa.

La existencia de este variado tejido de actividades creativas enmarca la génesis y consolidación de Las Bodas de Isabel de Segura y ha impulsado su celebración posterior. Es sabido que las personas con un determinado nivel cultural y actividad laboral demandan y se sienten atraídas por determinados productos culturales y que encuentran agradables las condiciones de vida que ofrecen los lugares pequeños (McGranahan et al., 2007). Por ello, los modelos teóricos al sistematizar las etapas de desarrollo de actividades creativas o culturales en las pequeñas ciudades y en las áreas rurales, coinciden en afirmar la conveniencia de que existen determinados antecedentes que faciliten la puesta en marcha de la actividad (Shifferd, 2005). Esta emerge también merced al liderazgo ejercido por algún actor o grupo de actores relevante y con la existencia de actividades de tipo informal que hacen posible la participación de la población. El desarrollo constituye otra etapa en la que se dan hechos como el trabajo coordinado y la colaboración de los participantes; la realización con regularidad de actividades artísticas u otras vinculadas a la iniciativa; el alcance de una masa crítica de participantes activos y la formación de un grupo de apoyo permanente. La iniciativa alcanza la etapa de madurez cuando tiene un papel central en la economía local que además es percibido así; ello requiere en muchas ocasiones contar con espacios o equipamientos propios.

En la evolución de Las Bodas de Isabel de Segura podemos reconocer las etapas descritas pero con algunas peculiaridades, como muestra el cuadro 4. 
Cuadro 4. Modelo evolutivo de la celebración de Las Bodas de Isabel de Segura.

\begin{tabular}{|c|c|c|c|c|c|}
\hline $\begin{array}{l}\text { Antecedentes } \\
\text { (antes de 1997) }\end{array}$ & \multicolumn{2}{|c|}{$\begin{array}{c}\text { Fase emergente } \\
(1997-2005)\end{array}$} & \multicolumn{2}{|c|}{$\begin{array}{l}\text { Fase de desarrollo } \\
(2005 \text { - hasta la fecha) }\end{array}$} & $\begin{array}{l}\text { Fase de madurez } \\
\quad \text { (pendiente) }\end{array}$ \\
\hline $\begin{array}{l}\text { Actitudes y valores } \\
\text {-Aprecio de los } \\
\text { jóvenes por el } \\
\text { teatro, la música, } \\
\text { las tradiciones, } \\
\text { la propia ciudad. } \\
\text { (Grupo musical } \\
\text { sefardí Artesonado) } \\
\text { - Valoración de la } \\
\text { historia local y de } \\
\text { la ciudad por una } \\
\text { parte significativa } \\
\text { de la ciudadanía } \\
\text { con hitos } \\
\text { históricos que } \\
\text { la han reforzado } \\
\text { (Asociaciones } \\
\text { culturales } \\
\text { que surgen o } \\
\text { se fortalecen, } \\
\text { Albishara) } \\
\text { - Tradición } \\
\text { histórica y } \\
\text { artística específica } \\
\text { de la ciudad } \\
\text { (Mudéjar, Leyenda } \\
\text { de los amantes) } \\
\text { - Precedentes } \\
\text { (Representación } \\
\text { en los años } \\
\text { cincuenta) }\end{array}$ & $\begin{array}{l}\text { Liderazgo en la } \\
\text { organización } \\
\text { - Configuración } \\
\text { de redes para } \\
\text { su promoción. } \\
\text { Patrocinio del } \\
\text { ayuntamiento } \\
\text { (1999) } \\
\text { - Integración en } \\
\text { la Federación } \\
\text { de Recreaciones } \\
\text { Históricas } \\
\text { - Asesoramiento } \\
\text { externo (Antonio } \\
\text { Gargallo et } \\
\text { al., Instituto } \\
\text { de Estudios } \\
\text { Turolenses) } \\
\text { - Mercadillo } \\
\text { medieval } \\
\text { - Talleres de danzas } \\
\text { medievales } \\
\text { - Talleres de luchas } \\
\text { de espadas } \\
\text { - Talleres de trajes } \\
\text { medievales } \\
\text { - Talleres de cuero } \\
\text { - Nuevos grupos de } \\
\text { teatro medievales: } \\
\text { Siglo XIII, } \\
\text { Dramatis Turolis, } \\
\text { El Candil. etc.... }\end{array}$ & \multirow{3}{*}{$\begin{array}{l}\text { Reconocimiento y } \\
\text { crecimiento } \\
\text { - Fundación Bodas } \\
\text { de Isabel de } \\
\text { Segura (2005) } \\
\text { - Financiación } \\
\text { externa } \\
\text { - Reconocimiento } \\
\text { por los ciudadanos } \\
\text { (participación } \\
\text { creciente y } \\
\text { masiva) } \\
\text { - Ampliación de las } \\
\text { redes que apoyan } \\
\text { el proyecto } \\
\text { (Reglamento } \\
\text { de los grupos, } \\
\text { organizados como } \\
\text { Federación, en } \\
\text { 2005) } \\
\text { - Ocupación de } \\
\text { lugares centrales y } \\
\text { emblemáticos de } \\
\text { la ciudad } \\
\text { - Cobertura en } \\
\text { medios de } \\
\text { - Intercambios } \\
\text { nacionales. } \\
\text { remunicación, } \\
\text { regionales y } \\
\text { nacionales } \\
\text { - Percepción de } \\
\text { los estímulos } \\
\text { económitornicos de la } \\
\text { fiesta: hostelería, } \\
\text { comercio } \\
\text { especializado, } \\
\text { restauración } \\
\text { - Atracción de } \\
\text { actividades } \\
\text { creativas de otros } \\
\text { intes }\end{array}$} & \multirow{3}{*}{$\begin{array}{l}\text { - Actividades } \\
\text { regulares en } \\
\text { diversos campos } \\
\text { artísticos } \\
\text { y sociales: } \\
\text { conciertos, } \\
\text { dramatizaciones, } \\
\text { musicales, } \\
\text { exhibiciones, } \\
\text { conferencias y } \\
\text { cursos } \\
\text { - Masa crítica } \\
\text { creciente } \\
\text { de actores y } \\
\text { colaboradores } \\
\text { - Consolidación } \\
\text { de un grupo } \\
\text { organizador } \\
\text { estable } \\
\text { - Redes y sinergias } \\
\text { entre grupos } \\
\text { artísticos } \\
\text { - Reconocimiento } \\
\text { institucional: } \\
\text { - 2007: Fiesta de } \\
\text { Interés Turístico } \\
\text { Regional } \\
\text { - 2008: premio } \\
\text { de la Fundación } \\
\text { Aragonesista } \\
\text { - 2009:Tramitación } \\
\text { de la certificación } \\
\text { de calidad ISO } \\
\text { 9001 } \\
\text { - Aumento del } \\
\text { sentimiento cívico } \\
\text { e identificación } \\
\text { con la iniciativa } \\
\text { - Participación } \\
\text { abierta a personas } \\
\text { de todas las } \\
\text { edades. }\end{array}$} & $\begin{array}{l}\text { Integración del } \\
\text { sector artístico } \\
\text { - Reconocimiento } \\
\text { externo por } \\
\text { profesionales } \\
\text { y gestores del } \\
\text { mundo teatral, } \\
\text { artístico } \\
\text { - Localización de } \\
\text { un barrio o área } \\
\text { local como lugar } \\
\text { creativo y artístico } \\
\text { (pendiente) } \\
\text { - Información, } \\
\text { divulgación y } \\
\text { formación (A } \\
\text { través de la } \\
\text { Fundación Bodas } \\
\text { de Isabel) }\end{array}$ & \multirow[t]{3}{*}{$\begin{array}{l}\text { - Círculo virtuoso } \\
\text { de atracción de } \\
\text { artistas y gente } \\
\text { creativa ajena por } \\
\text { los artistas locales } \\
\text { - Profesionalización } \\
\text { de algunos grupos. } \\
\text { (Les Morenillas) } \\
\text { - Negocios } \\
\text { relacionados con } \\
\text { la recreación. } \\
\text { (todavía } \\
\text { minoritarios y } \\
\text { estacionales) } \\
\text { - La recreación } \\
\text { es un elemento } \\
\text { central en las } \\
\text { estrategias } \\
\text { de desarrollo } \\
\text { local (Ni la } \\
\text { administración } \\
\text { regional ni la local } \\
\text { le concede aún ese } \\
\text { papel) } \\
\text { - Instalaciones } \\
\text { propias específicas } \\
\text { en el ámbito } \\
\text { artístico (No } \\
\text { existen) } \\
\text { - Estructura } \\
\text { organizativa } \\
\text { robusta que } \\
\text { incluye } \\
\text { información, } \\
\text { difusión y } \\
\text { formación } \\
\text { (Fundación Bodas } \\
\text { de Isabel de } \\
\text { Segura) }\end{array}$} \\
\hline $\begin{array}{l}\text { Líderes que } \\
\text { encienden la mecha } \\
\text { - Asociación } \\
\text { de Mujeres } \\
\text { Empresarias, } \\
\text { con mentalidad } \\
\text { emprendedora y } \\
\text { fondos europeos } \\
\text { - Experiencia vital } \\
\text { y académica en } \\
\text { áreas artísticas. } \\
\text { - Conocimiento } \\
\text { de festivales y } \\
\text { recreaciones } \\
\text { similares } \\
\text { - Conocimiento de } \\
\text { la realidad cultural } \\
\text { local y contactos } \\
\text { - Capacidad de } \\
\text { movilizar agentes } \\
\text { locales y grupos } \\
\text { latentes }\end{array}$ & \multirow[t]{2}{*}{$\begin{array}{l}\text { Actividad artística } \\
\text { - Configuración de } \\
\text { redes promotoras. } \\
\text { - Prácticas } \\
\text { artísticas, teatrales, } \\
\text { musicales, } \\
\text { con grupos } \\
\text { surgidos como } \\
\text { consecuencia del } \\
\text { proyecto. } \\
\text { - Prácticas } \\
\text { colectivas } \\
\text { vinculadas a la } \\
\text { actividad: } \\
\text { - 1998: Talleres de } \\
\text { costura; charlas } \\
\text { - 1999: Casting } \\
\text { de artistas que } \\
\text { seguirá con } \\
\text { convocatoria } \\
\text { abierta todos los } \\
\text { años } \\
\text { 2000: Concurso } \\
\text { de guiones } \\
\text { - 2001: Concurso } \\
\text { carteles }\end{array}$} & & & $\begin{array}{l}\text { Apoyo financiero } \\
\text { público y privado } \\
\text { - Subvención del } \\
\text { FITE (Fondo de } \\
\text { Inversiones para } \\
\text { Teruel) } \\
\text { - Ampliación y } \\
\text { diversificación de } \\
\text { patrocinadores } \\
\text { Angels business } \\
\text { locales (Caja Rural } \\
\text { de Teruel) } \\
\text { - Compromiso } \\
\text { financiero } \\
\text { individual de } \\
\text { los ciudadanos } \\
\text { (cuotas por } \\
\text { pertenecer a } \\
\text { los grupos } \\
\text { medievales) }\end{array}$ & \\
\hline $\begin{array}{l}\text { Sucesos } \\
\text { catalizadores } \\
\text { - Celebración del } \\
14 \text { de febrero } \\
\text { de } 1997 \text { con } \\
\text { representaciones } \\
\text { en la calle }\end{array}$ & & & & $\begin{array}{l}\text { Reforzamiento del } \\
\text { turismo local }\end{array}$ & \\
\hline
\end{tabular}

Fuente: Elaboración propia a partir de Shifferd, 2005. 
Como se expresa en el cuadro 4 , las condiciones previas que facilitan la aparición de un cluster creativo se dan en la ciudad de Teruel desde mitad del decenio de mil novecientos noventa. Existe un patrimonio inmaterial relevante, y entre otras historias y sucesos destaca la leyenda de los amantes que es muy conocida y valorada como propia por los ciudadanos y ya había sido con anterioridad tratada en estudios científicos y en el marco de la divulgación. Además, su condición de ciudad universitaria y la existencia de grupos especializados en Historia medieval y centros de investigación como el Centro de Estudios Mudéjares y el Instituto de Estudios Turolenses, favorecen la existencia de un trasfondo académico en cuyo ámbito han surgido diferentes iniciativas con rigor documental. Por otra parte, el elevado nivel de instrucción de una parte importante de su población así como su nivel de renta, han generado una demanda potencial sensible a cualquier iniciativa innovadora cultural y de ocio que se plantee.

La posibilidad de contar con programas formativos europeos para fomentar la iniciativa emprendedora y la puesta en valor de los recursos locales, hicieron tambien posible que personas dinámicas pusieran en marcha diferentes negocios gracias a activos inmateriales de este tipo. Así se explica que un curso del Fondo Social Europeo, enfocado a actividades empresariales impulsadas por mujeres, decidiera que dos de sus participantes iniciaran la aventura cultural de Las Bodas en 1997.

\subsection{Estructura funcional de las actividades inducidas por la celebración}

En la celebración de Las Bodas de Isabel de Segura, están presentes en mayor o menor grado los diferentes componentes que pueden configurar el sistema que avala y soporta el desarrollo de actividades creativas en un contexto dado, conformando el germen de un posible cluster de actividades creativas. La información recogida sobre la celebración pone de manifiesto la existencia de numerosos y diversos tipos de agentes, empresas, instituciones u organizaciones actualmente implicados en la misma (v. cuadro 5).

Cuadro 5. Componentes del posible cluster de actividades creativas en torno a Las Bodas de Isabel de Segura

\begin{tabular}{|c|c|c|c|c|c|c|}
\hline $\begin{array}{l}\text { Tipos } \\
\text { de componentes }\end{array}$ & \multicolumn{6}{|c|}{$\begin{array}{l}\text { Instituciones, actividades, servicios, y empresas involucradas } \\
\text { en la celebración (1) }\end{array}$} \\
\hline $\begin{array}{l}\text { Instituciones } \\
\text { asociadas }\end{array}$ & Patrocinadores & \multicolumn{2}{|c|}{$\begin{array}{l}\text { Fundación Bodas de Isabel de } \\
\text { Segura }\end{array}$} & $\begin{array}{c}\text { Ayuntamiento/ } \\
\text { Gobierno } \\
\text { autonómico }\end{array}$ & \multicolumn{2}{|c|}{$\begin{array}{l}\text { Federación de Asociaciones } \\
\text { de Grupos Históricos }\end{array}$} \\
\hline $\begin{array}{l}\text { Firmas } \\
\text { creativas }\end{array}$ & Artesanos & $\begin{array}{l}\text { Confección } \\
\text { de trajes, } \\
\text { instrumentos } \\
\text { musicales }\end{array}$ & $\begin{array}{l}\text { Grupos de } \\
\text { teatro y danza }\end{array}$ & $\begin{array}{l}\text { Mercado } \\
\text { medieval } \\
\text { asociado }\end{array}$ & \multicolumn{2}{|c|}{ Grupos recreacionistas } \\
\hline $\begin{array}{l}\text { Proveedores } \\
\text { especializados }\end{array}$ & $\begin{array}{l}\text { Compañias de } \\
\text { imagen y sonido }\end{array}$ & $\begin{array}{l}\text { Investigadores } \\
\text { Historiadores }\end{array}$ & $\begin{array}{l}\text { Escritores } \\
\text { (guionistas) }\end{array}$ & $\begin{array}{l}\text { Cursos de } \\
\text { formación }\end{array}$ & $\begin{array}{l}\text { Selección de } \\
\text { actores }\end{array}$ & $\begin{array}{l}\text { Alimentos } \\
\text { históricos }\end{array}$ \\
\hline $\begin{array}{l}\text { Otros } \\
\text { proveedores }\end{array}$ & $\begin{array}{c}\text { Medios de } \\
\text { comunicación }\end{array}$ & $\begin{array}{c}\text { Organizadores de } \\
\text { eventos }\end{array}$ & $\begin{array}{l}\text { Organización } \\
\text { de Concursos }\end{array}$ & $\begin{array}{l}\text { Comercio } \\
\text { relacionado }\end{array}$ & $\begin{array}{l}\text { Hostelería } \\
\text { Transporte } \\
\text { Servicios }\end{array}$ & $\begin{array}{c}\text { Agencias } \\
\text { de viajes y } \\
\text { turismo }\end{array}$ \\
\hline
\end{tabular}

(1) En cursiva, componentes pertenecientes a los tipos de actividades creativas establecidas en el cuadro 1

Fuente: Entrevistas estructuradas. Elaboración Propia

En las funciones y actividades identificadas en el cuadro 4, pueden reconocerse las diferentes etapas del clásico esquema de la cadena de valor referida a la recreación turolense, que queda configurada conforme a la siguiente secuencia:

Figura 2. Elementos de la cadena de valor de Las Bodas de Isabel de Segura

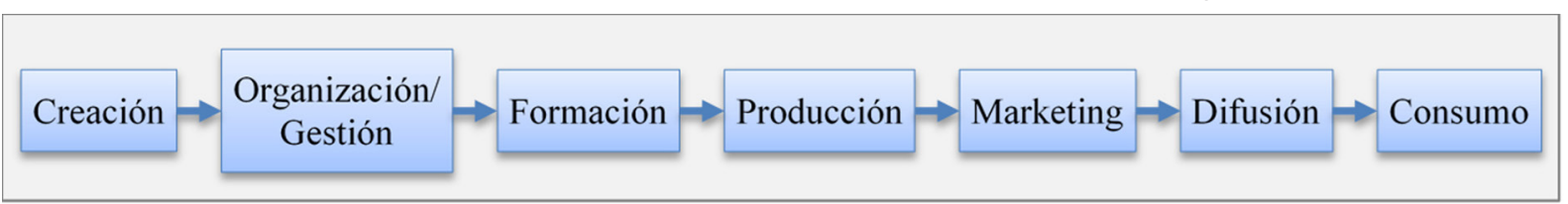

La reclasificación de los integrantes de la celebración conforme a la secuencia expuesta se presenta en el cuadro 6. 
Cuadro 6. Tipos de entidades participantes en Las Bodas de Isabel de Segura y función que desempeñan en la cadena de valor de la celebración ${ }^{4}$

\begin{tabular}{|c|c|c|c|}
\hline Función & Tipo entidad & Función & Tipo entidad \\
\hline \multirow{5}{*}{$\begin{array}{l}\text { Organización/ } \\
\text { gestión }\end{array}$} & \multirow{2}{*}{ Fundación } & \multirow{5}{*}{$\begin{array}{l}\text { Producción } \\
\text { (continuación) }\end{array}$} & Alimentación historicista \\
\hline & & & Catering \\
\hline & Patrocinadores & & Grupos recreacionistas \\
\hline & \multirow{2}{*}{ Administraciones públicas } & & Peñas ( 1 ) y afines \\
\hline & & & Asociación Mercado medieval \\
\hline \multirow{4}{*}{ Creación } & \multirow{3}{*}{ Investigadores } & \multirow{4}{*}{ Comercialización } & Organizadores concursos \\
\hline & & & Comercio relacionado con la fiesta \\
\hline & & & Hostelería/Transporte/servicios \\
\hline & Guionistas & & Administración local \\
\hline \multirow{2}{*}{ Formación } & Promotores cursos & \multirow{4}{*}{ Difusión } & Material impreso y medios \\
\hline & Promotores de castings & & Organizadores eventos \\
\hline \multirow{4}{*}{ Producción } & Artesanos & & Agencias turismo \\
\hline & $\begin{array}{l}\text { Talleres (indumentaria, } \\
\text { Instrumentos musicales) }\end{array}$ & & Material impreso y medios \\
\hline & Grupos teatro & \multirow[b]{2}{*}{ Consumo } & Población local \\
\hline & $\begin{array}{l}\text { Empresas de sonido, } \\
\text { electricidad }\end{array}$ & & Visitantes \\
\hline
\end{tabular}

(1) Asociaciones de residentes formalmente constituidas para el desarrollo de actividades recreativas

Fuente: Elaboración propia

El papel de los investigadores y recreacionistas ha sido clave, ya que han rastreado las referencias históricas en relación con los protagonistas de la leyenda. También se han centrado en identificar el ambiente, los atuendos y los componentes de la sociedad de principios del siglo XIII. Esta función es, de algún modo, compartida con los guionistas de las representaciones teatrales o los cartelistas. En cuanto a la organización y gestión, es incuestionable la el papel de la Fundación Bodas de Isabel, que además contrata al Mercado Medieval, y ex equo la del Ayuntamiento, pero hay que tener también en cuenta la importancia que tiene en la estructura funcional organizativa, el Comité Medieval, síntesis de diversos agentes que hacen posible la fiesta, y de modo más concreto, la federación de Asociaciones de grupos Históricos, tal y como opinan los técnicos:

En realidad el Comité fue un acierto total porque...son los mismos intereses pero ...cada uno los entiende de una manera, y la cordura... la tiene que poner quien preside, ... discutimos de todo lo que tenemos que discutir... se habla de todo...es un sistema muy bueno....se intentó generar un borrador de reglamento para coordinar toda la Fiesta, pero al final hay cosas que no se sabe si es mejor reglamentarlas o no... (Técnico del Ayuntamiento de Teruel)

Las siguientes etapas de la secuencia tienen una entidad desigual. El capítulo formativo es interesante, ya que la recreación dramática ha dado lugar a la organización de cursos de teatro y de danza y a la aparición de talleres de confección de vestimentas, uno de ellos como fruto inmediato del programa emprendedor para mujeres, y de accesorios de época, que han enlazado con la función productiva al apoyar la creación de algunas empresas y consolidar otras ya existentes, especializadas en confección a medida, un negocio que parecía extinguirse. Las Bodas han contribuido a potenciar el desarrollo local por su impacto en algunos servicios como la hostelería, pero también en otras actividades como imagen y sonido o imprenta; y por su relación con la industria que, aunque de forma más modesta, ha permitido consolidar algunas actividades relacionadas con la confección, la ornamentación urbana de todo tipo e incluso la

4 En el trabajo de campo hemos entrevistado a representantes de las siguientes funciones: Organización y Gestión (Fundación Las Bodas de Isabel, Ayuntamiento de Teruel, Cámara de Comercio), creación (Instituto de Estudios Turolenses; expertos en equipamientos e instalaciones para recreaciones históricas), producción (propietarios de talleres de indumentaria) y servicios (gerentes de establecimientos hoteleros, empresa de turismo activo). La entrevista era semiestructurada y el cuestionario similar pero adaptado a cada uno de los actores según la información que nos interesaba recabar. 
elaboración de alimentos o bebidas específicos de inspiración histórica. La comercialización, además de lo que significa en esta línea el Mercado Medieval, cuyos puestos venden artesanía de diversos tipos, ha dado lugar al incremento del comercio de tejidos, al montaje de tiendas de recuerdos relacionadas con la fiesta y lo medieval y al incremento de muchos servicios, especialmente de hostelería. La difusión, por su parte, ha involucrado a los medios de comunicación regionales y a los expertos diseñadores de una página web y de una revista el línea, mientras que de modo indirecto algunos de los patrocinadores han colaborado igualmente, en la publicidad con su propia aportación a la fiesta (caso de una conocida marca de cerveza). Todo ello confirma su interés en aspectos como la búsqueda de nuevos nichos de mercado e iniciativas emprendedoras potenciales.

La celebración de Las Bodas, como todo acontecimiento cultural, necesita una financiación fija que está en torno a los 240.000 euros, y sobre la que recogemos diversos comentarios de varios de los entrevistados. La mayor parte de esta cantidad la proporciona el Ayuntamiento, incluyendo todos los años una partida en sus presupuestos para este fin. En las dos últimas ediciones, una cantidad sustancial debía proceder del Fondo de Compensación Interterritorial para Teruel (FITE), lo que está siendo objeto de controversia dada la finalidad inversora del mismo, y la condición de gasto corriente que presentan la mayoría de las partidas presupuestarias asignables a la fiesta.

El Ayuntamiento de Teruel tiene una partida presupuestaria ... de más de 100.000 euros...Pero este año serán unos $75.000 \ldots$ El FITE ... de 2012 está concedido pero no materializado... y el de 2013 está comprometido pero no está activo todavía... De momento no han recibido el dinero ni del FITE del año pasado ni el de éste. El montante mayor no ha sido entregado porque todavía no lo han recibido (Técnico del Ayuntamiento de Teruel)

Otros promotores, como el gobierno regional, la Caja Rural y la Asociación de Empresarios aportan diversas cantidades y hay colaboradores que proporcionan además algún servicio. Es el caso de la Cámara de Comercio o de un grupo hostelero:

Si hubiéramos tenido la capacidad económica hubiéramos podido estar en estos proyectos desde el principio...

Ahora...en la Partida de Diego [secuela de la Fiesta que se celebra en octubre], hemos colaborado a través del

Programa Comunitario Alimentos de Teruel, en el suministro de las tropas, en publicidad... y estamos siempre a disposición de quien nos solicite (representante de la Cámara de Comercio de Teruel)

El grupo ... colabora desde el principio: cede habitaciones, [la gerente de la Fundación] vive en el hotel durante las mismas, de aquí sale el entierro, aglutina cientos de personas (representante del grupo hotelero).

Determinadas empresas patrocinadoras colaboran igualmente, pero en función de los beneficios que a ellos les proporciona, tal como expresa la Gerente de la Fundación:

Creo que entre los [patrocinadores] deberíamos distinguir los que tienen un papel estratégico relevante y los que sólo tienen un interés coyuntural, comercial, de rentabilizar el nombre de su empresa o entidad, pero sin más...

Por mucho dinero que aporten... su negocio real, global, depende muy poco del evento (Gerente de la Fundación Bodas de Isabel de Segura)

Finalmente hay que añadir que una parte de los ingresos procede de las cuotas que se cobra a los que instalan puestos del Mercado Medieval. De ello, inicialmente se encargaba el Ayuntamiento, pero desde la creación de la Fundación lo hace ésta, remitiendo un pequeño porcentaje al consistorio, que a su vez aporta infraestructuras y se hace cargo de los servicios de limpieza, seguridad, u otros lo que supone un montante de importancia:

Inicialmente, cuando se contrataba desde aquí [el mercado medieval], repercutía al 100\% al Ayuntamiento... Desde que se creó la Fundación, ya son ellos los que cobran la ocupación y parte la tienen que ingresar en el Ayuntamiento, pero hay una cantidad [con la que] financian parte de la Fiesta...El Ayuntamiento, solo cobramos para cubrir el coste de los servicios que se prestan... podemos estimar que el ingreso que se realiza es bastante notable, estamos hablando de unos 30.000 euros de tasas, pero claro, el desgaste de suelo, de reposición...limpieza.. se suele superar siempre y si hablamos del entorno, aproximativo, entre unos 30.000-50.000 euros que se colocan, también puedo decir el número de puestos que ha habido en el mercadillo en estos últimos años, en torno a los 200... (Técnicos de turismo y desarrollo local del Ayuntamiento de Teruel)

\subsection{Los vínculos e interdependencias entre las entidades participantes en Las Bodas de Isabel}

Sin duda surge una pregunta ilas relaciones comerciales y la aparición de redes inspiradas en la confianza compartida o capital social (Camagni, 2003), en las que abundan informaciones relevantes difundidas de manera espontánea, tipo buzz, culminan en un cluster creativo? Un elemento constitutivo de 
este, y que lo acredita como tal, es la existencia de interdependencias entre sus diversos integrantes, ello les hace ser más eficientes, obtener niveles de utilidad más elevados y generar externalidades positivas (Laffon, 2008). Los testimonios recogidos, indican que tales interrelaciones se dan de forma tácita entre todos los sectores que intervienen en las diferentes fases de la cadena de valor de Las Bodas de Isabel Segura. No obstante, hay que tener en cuenta, que sólo en algunos casos, las relaciones tácitas se traducen en relaciones formales o cuantificables. Estas relaciones son, a su vez, de carácter económico y de carácter social. Las primeras inciden más en el concepto de cluster convencional, y las segundas ahondan en matices de las actividades creativas y de sus atractivos para los residentes. Entre los vínculos cuantificables financieramente, destacan los mantenidos con el sector de la hostelería, como reconoce el gerente del principal grupo hotelero en la provincia:

Se ha conseguido la total ocupación de los hoteles de Teruel capital e incluso llega a llenarlos hasta $35 \mathrm{kms}$ alrededor. En la fecha de la celebración los hoteles cuelgan el cartel de completo, con unas tarifas de temporada alta. Además el tipo de viajero que llega a la ciudad es de mayor poder adquisitivo que en "Vaquillas (fiestas populares de julio).

El subsector de restauración, aún más que el de alojamiento, experimenta en mayor medida el impacto, pues gran parte de los asistentes viajan en el día desde Valencia o poblaciones inmediatas, por lo que su principal gasto es en alimentación y bebida, de modo que como comentaba otro de los entrevistados,

La restauración genera una cajas diarias del $800 \%$ más que un fin de semana normal... Dos o tres días en la calle, por supuesto la hostelería es la que más se beneficia.

Nuestro interlocutor en la Cámara de Comercio citaba también otros sectores, como el de la confección de trajes medievales y complementos:

Aparte del beneficio de la hostelería, ha generado una industria paralela: el tema de los trajes ... que se ha creado al amparo de Las Bodas y lo que esto conlleva, lonas para las jaimas....

Según otros entrevistados, sin embargo, el sector de la indumentaria ha tenido su ciclo de negocio a lo largo de estos diez años de existencia, y tras un auge inicial se encuentra en una fase muy madura, pues algunos negocios han cerrado o disminuido sustancialmente sus ingresos por este motivo, como nos contaba nuestro interlocutor en el Ayuntamiento de Teruel:

Inicialmente tuvo y ha tenido un impacto interesante porque se crearon varias escuelas taller de indumentaria, de

cuero... Estos talleres además de estos trajes medievales ... hacían los de Semana Santa...y luego ya no sé cuál fue

el conflicto...quizás pertenece al ámbito particular ....el caso es que cerraron.

Y un emprendedor de turismo activo y medieval, que tiene una empresa en una localidad cercana, incidía también en el carácter cíclico y todavía inicial, zigzagueante, del proceso:

Al principio tuvo muchísimo tirón, un boom muy grande... todo el mundo se hacía el traje y a veces uno cada año.

Pero ahora con la crisis, el que tiene uno o más no se hace otro.

Es decir, los sectores más vinculados entre sí, que experimentan las consecuencias positivas de esta actividad creativa, son los vinculados con el consumo de residentes, por la demanda adicional de éstos en vestidos tradicionales, comidas en grupos, gasto en ocio; y con el consumo in situ de los turistas, cuyo gasto se redirige en mayor medida hacia el alojamiento, hostelería, transporte así como a algunas compras artesanales o de comidas típicas del lugar.

Entre los proveedores de inputs cualificados, refiriéndonos a servicios creativos más sofisticados de publicidad, informática, diseño, u otros, según nos decía el secretario de la Cámara de Teruel "hay gente competente en Teruel. Todo se hace en Teruel", sin embargo, la capacidad de arrastre es reducida, al tratarse de una festividad concentrada en pocos días y con un mercado local reducido. La fiesta es, por lo tanto, muy relevante en cuanto al capital relacional (Cagmagni, 2003) pero no tanto con relación con las externalidades positivas sobre la estructura productiva turolense, como se argumenta en el siguiente epígrafe.

\subsection{Las repercusiones económicas de la celebración}

El estudio llevado a cabo hasta el momento pone de manifiesto algunos aspectos del impacto de esta fiesta en la economía local, aunque se trata de una primera aproximación pendiente de cuantificar hasta que dispongamos de más datos. No obstante, de las entrevistas pueden deducirse diferentes cuestiones de interés. Desde la perspectiva de la demanda, los consumidores de los bienes y servicios ofertados en re- 
lación con la recreación, el incremento del número de participantes y visitantes ha sido constante. Según la oficina de Turismo, se cifran en 30.000 el número de visitantes, cifra que casi iguala la de la población residente (34.000 habitantes). Sin embargo, al tratarse de una fiesta abierta y gratuita, cuyos principales actos se celebran en la calle, es difícil determinar el consumo efectivo de los asistentes:

Es difícil de cuantificar. Porque es gratis. Una cosa es decir que han pasado por Turismo 30.000 personas, pero hay que ver cuánto se gastan esas personas, Porque hay gente que viene a pasar el día, se traen bocadillos, y entonces el impacto es cero (empresario; miembro de la Junta de la Federación de Asociaciones de Grupos Históricos)

Desde el primer año se ha conseguido superar las ventas aproximadamente en torno a un 5\% más cada año...la gente de Teruel se toma Las Bodas muy en serio y acuden familiares de fuera como invitados de los turolenses. En Las Bodas hay unas 20.000 personas de fuera, pero no todos se alojan en hoteles (representante de grupo hotelero)

No poseemos datos económicos para cifrar la repercusión que la fiesta pueda tener en la economía turolense. No obstante, a simple vista se ve, tanto por la afluencia de forasteros, como por la presencia de puestos de mercadillo, por ejemplo. En reportajes del Diario de Teruel hemos leído manifestaciones de los artesanos sobre la buena acogida y ambiente del mercado turolense durante los días de la fiesta. Teniendo en cuenta que un aspecto importante de la misma es la actividad en las llamadas jaimas, con las comidas, meriendas, cenas, etc., suponemos que los ingresos de los comerciantes y de los establecimientos de hostelería serán positivos (exdirectora del Instituto de Estudios Turolenses)

Las entrevistas han puesto de relieve que el impacto más importante ha sido en hostelería, con hoteles ocupados al completo, no solo en la propia ciudad sino en un radio de $50 \mathrm{Km}$. Ello favorece la contratación temporal de algunas personas, tal como nos indicó el representante del grupo hotelero entrevistado. El comercio ha sido otros de los sectores beneficiados, especialmente el de alimentación, tejidos y complementos, si bien hay que advertir que en estos casos los consumidores son, mayoritariamente, los propios turolenses, tal como indican nuestros entrevistados:

En Teruel sí que se nota mucho en el tema de tiendas de confección, que estaban de capa caída, y en los primeros años se vendió telas, pasamanería...que es una cosa que estaba ya tan en el olvido,... hora hay tres o cuatro tiendas o cinco (Técnico, Ayuntamiento de Teruel)

Hay que tener en cuenta el gasto y los ingresos que se generan ...por la propia gente. Son personas que ...antes de arrancar ya tienen 1.500-2.000 euros de gasto aqui en Teruel... y luego ....material a consumir todos los años ... comida, bebida....en mi grupo pagamos cada socio 100 euros al año y somos 48 personas, o sea 48.000 euros, otros grupos incluso pagan más. Y somos 6.000 personas [en la Federación de Asociaciones de Grupos Históricos], a una media de 100 euros por persona, son 600.000 euros, que es lo que nos gastamos en Teruel, en su Fiesta, lo que deja la propia Federación, la propia gente interna, no el turista. Así que es mucho mayor el impacto interno que el externo, a nuestro entender (empresario, miembro la Junta Directiva de la Federación de Asociaciones de Grupos Históricos)

El impacto en el sector productivo, aunque más modesto, ha sido interesante; se trata de empresas pequeñas que han surgido en el ámbito de las actividades creativas, como artesanos, talleres de confección histórica o turismo y ocio cultural. A partir de la organización de diversos talleres formativos por parte del Ayuntamiento, surgen las primeras empresas de confección de atuendos medievales y de complementos, que son las más importantes por derivar directamente de la celebración, e igualmente se elaboran algunos alimentos especiales como recreación medieval así como diversos tipos de artesanía.

Tuvo ... impacto porque se crearon varias escuelas taller de indumentaria, de cuero...El primer año fue el taller de confección de trajes medievales; se formó con 20 mujeres mayores de 25 años; este taller se cerró en 2003 y se constituyeron en cooperativa...Estas empresas de confección siguen trabajando...hay dos o tres empresas que confeccionan trajes (Técnico del Ayuntamiento de Teruel)

La fiesta ha dado lugar a la formación de empresas... la más importante es [nombre de la empresa], aunque hay varias más pequeñas, pero el que más ha trabajado es [nombre de la misma empresa]. Y ahora ya no trabaja tanto para Las Bodas; vende fuera, porque el mercado local está bastante saturado. Al principio tuvo muchísimo tirón, un boom muy grande, porque todo el mundo se hacía el traje y a veces uno cada año. (empresario, miembro de la Junta Directiva de la Federación de Asociaciones de Grupos Históricos)

Cabe destacar también que Las Bodas de Isabel de Segura han suscitado la organización de conciertos; la puesta en marcha de diversos talleres artesanos por parte de grupos de la federación recreacionista; la formación de grupos de teatro y danza y la celebración de algunas representaciones complementarias, 
como la Partida de Diego. Un grupo musical especializado en canción sefardí, ha pasado en estos años del campo amateur al profesional. En Teruel destacan profesionales y empresas muy cualificadas de informática, publicidad o artes gráficas que están colaborando con la celebración. Sin embargo, todos los entrevistados están de acuerdo en que su capacidad de arrastre es limitada, por ser una festividad concentrada en pocos días y por la reducida dimensión del mercado local. El sector servicios, aunque tiene un efecto positivo, especialmente en la hostelería y el ocio, tiene el grave problema de que no puede acumular su producción: la oferta limitada de una ciudad de 30.000 habitantes se encuentra desbordada por una demanda muy superior, cuya atención no puede diferir a otros momentos posteriores. En opinión de uno de los entrevistados,

Se podría apostar por la semana previa o dos semanas antes, generar unas rutas turísticas; El acueducto, por ejemplo, o la ruta del amor... se podría plantear de otra forma, pero nos centramos en fiesta, fiesta, fiesta...y al final la Fiesta tiene su público, pero claro, [para quien gusta de algo] un poco más serio o ver otro tipo de cosas.. las semanas previas [podría organizarse] un ciclo de conferencias...(empresario, miembro de la Junta Directiva de la Federación de Asociaciones de Grupos Históricos)

\subsection{Aspectos del impacto de Las Bodas de Isabel de Segura. Identidad local, capital social y difusión espacial}

Un comentario repetido a propósito de la fiesta en relación con el futuro es que "Tiene posibilidades de recorrido". O también, que "...El tema de los Amantes es un filón".

Ciertamente se trata de una fiesta en vías de consolidación y con muchos ámbitos perfeccionables. Según el gerente del principal grupo hotelero sería preciso reforzar los vínculos con otras actividades creativas:

No se ha hecho nada o muy poco para el desarrollo de actividades culturales. En este sentido, hay falta de emprendedores. No se ha trabajado en estas cuestiones..

Y añade:

El sector público debería de volcarse más de lo que lo hace al ser un momento clave para vender Teruel al exterior. Este tema yo creo que no se hace bien. Debería de haber más medios de comunicación a nivel nacional e incluso internacional...Falta publicidad y ello resta clientela. En parte se solucionará si la fiesta adquiere el rango de fiesta nacional, ya que se incluye en unos canales especiales de difusión.

La necesidad de una mayor implicación del sector público aparece también en otros testimonios, en relación con mejoras en las infraestructuras y en el desarrollo local.

Es una actividad que ayuda a "poner a Teruel en el mapa", pero mientras tengamos estas comunicaciones tan deficientes, véase el ferrocarril, da igual todo lo demás... y que supone una ayuda económica, no cabe duda... Para conseguir todo lo anterior [un desarrollo y conexión mayor], el Ayuntamiento y otras instituciones como la Cámara de Comercio, la Denominación de Origen, Bancos y otras entidades, tienen que tener claro que la actividad cultural y recreativa genera valor añadido...(antigua directora del Instituto de Estudios Turolenses)

Es también opinión común que la conexión con otras recreaciones semejantes, no solo de ámbito nacional sino europeo, daría un mayor impulso a las actividades creativas. La Fundación es consciente de ello y ya tiene conexiones con recreacionistas franceses y, recientemente, con ciudades italianas. En esta línea, cabe destacar el ya citado I Congreso Internacional de Fiestas y Recreación Histórica en el que se puso en marcha un grupo de trabajo para potenciar la colaboración e intercambio de experiencias entre ciudades que comparten tradiciones y festividades afines.

Los vínculos de carácter social y personal, que aglutinan la confianza y refuerzan la identidad local y el compromiso con el territorio (Lundamark y Petterson, 2012), se han incrementado de modo notable. Lo sintetiza coloquialmente nuestro interlocutor en la Cámara de Comercio cuando expresa:

"Las Bodas han servido para recuperar el verdadero orgullo de tener los Amantes; es una de las claves, porque en

Teruel, el tema de los Amantes era una cosa que estaba ahí ...eso de "los amantes de Teruel, tonta ella y tonto él"

(ripio popular burlón)... Creo que muchos turolenses ni siquiera habían visto los Amantes, y ahora es un orgullo, todos hablan de los Amantes y lo defendemos a capa y espada y nos creemos a pie juntillas que pasó..."

Hoy en día una gran parte de los turolenses toma parte activamente en la fiesta, como actores de grupos de teatro -ámbito en el que destaca la composición y estreno con gran éxito de un espectáculo musical-; interviniendo en labores logísticas cualificadas como atrezzo u otras; en la coordinación de actos y su ambientación; en la representación de oficios tradicionales o deportes medievales, entre otros. 
Y lo hace de forma desinteresada, incluso durante los meses precedentes, como nos cuenta el vocal de la Federación de Grupos:

“...La Fiesta se siente como propia, toda la gente la siente y participa altruistamente y a los grupos de música les dices "oye, que queremos hacer esto", no cobran y la gente pone lo mejor de sí misma en esta Fiesta.... Somos 6.000 personas reguladas (en la Federación), pero se visten muchos más. Todo el mundo tiene al menos un traje en su armario..."

Un $20 \%$ de la población, aproximadamente, se responsabiliza de alguna tarea regulada. Adicionalmente, de forma espontánea, la mayoría de los turolenses participan como público, se visten, acogen familiares y amigos que vienen de otros lugares, sintiéndose orgullosos de la atención a los visitantes y reconocidos por ello. Estos y otros elementos recabados durante el trabajo de campo nos permiten afirmar que los vínculos de identidad han madurado y se han intensificado gracias a la celebración de Las Bodas. Es decir, la dotación de capital social se ha visto mejorada de forma significativa, aumentando la autoestima y la confianza entre sus gentes y afianzando sus señas de identidad.

El epicentro de esta recreación y fiesta es Teruel, aunque ha repercutido en su área de influencia inmediata. Además, la Fundación Bodas de Isabel de Segura colabora en otros acontecimientos similares, aportando su experiencia no solo en la zona más próxima sino en otros sectores de la provincia, como nos indican algunos de los testimonios:

Esos eventos...son...réplicas o recreaciones históricas que la Fundación ayuda a organizar en otros lugares: "La leyenda de la Zaida", en Cella, "Juan Palomero, el último morisco", en Gea, y otras más, en Cedrillas,.... (Gerente de la Fundación Bodas de Isabel de Segura)

A raíz del tirón que ha tenido [la celebración de Las Bodas] ha habido muchos pueblos en la provincia que han hecho fiestas medievales, ... se hacen muchas actividades y pueblos de la provincia de Teruel se han empezado a hacer sus propios pendones, su propia decoración, y ya no necesitan tanto de lo nuestro, pero eso ha servido de tirón para emplear la experiencia de Teruel y ... de las mujeres que se formaron en los talleres y....han hecho empresas (Técnico, Ayuntamiento de Teruel)

\section{CONCLUSIÓN}

Los fuertes desequilibrios territoriales españoles y del resto de Europa explican la búsqueda de nuevas vías de crecimiento en las áreas menos avanzadas. Las actividades creativas son una opción apropiada por las expectativas que suscitan y por dotar a estas áreas de ventajas competitivas. El patrimonio cultural, tanto material como inmaterial, es un importante recurso económico e impulsa la puesta en marcha de estrategias innovadoras que explotan el talento local y se adaptan a la personalidad del territorio. En el artículo hemos analizado la celebración en Teruel de Las Bodas de Isabel de Segura, como herramienta de desarrollo local en una pequeña ciudad y como un posible epicentro de cluster de actividades creativas.

Hemos recordado que estas actividades combinan lo público y lo privado y junto a actividades marcadas por emociones y sentimientos, en las que no cuentan precios ni mercados y, por lo tanto, no mercantilizadas, se generan diferentes negocios muy dinámicos, especializados en el ocio, la cultura y el atractivo residencial, con demandas crecientes. El efecto multiplicador de esta fiesta se refleja especialmente en el incremento y la diversificación de una oferta de servicios innovadores y personalizados, así como de labores artesanales, que requieren de un capital humano y emprendedor muy cualificado, aunque se trate de actividades tradicionales como la alimentación, hostelería, agricultura y, en menor medida, la actividad industrial. Unas empresas se conectan a otras de modo tácito dando lugar a una especialización relativa en actividades creativas pudiendo llegar a constituir clusters específicos en Teruel y su provincia.

El análisis llevado a cabo sobre las actividades creativas en Teruel, centrando la atención primordialmente en la teatralización de la leyenda de los Amantes, se ha basado en la realización de entrevistas semiestructuradas a actores de las fiesta como los representantes de los grupos, las empresas y las instituciones implicados. Ello nos ha permitido alcanzar algunas conclusiones provisionales que habrá que confirmar a partir de una profundización mayor en la investigación de este tema. Ha quedado patente, en primer lugar, que la herencia cultural, como bien intangible, puede llegar a adquirir un nuevo significado como recurso económico. Así se puede afirmar que la celebración de Las Bodas de Isabel de Segura ha generado relaciones de carácter comercial, organizativo y funcional entre muchos de los participantes, estimulando la economía local. En segundo lugar es también evidente que ha reforzado la identidad de los habitantes, el capital social de la ciudad y la marca turística y cultural asocida a Teruel. 
Sin embargo, debemos admitir, en tercer lugar, que esta iniciativa no conforma todavía un cluster de actividades creativas, si bien se plantea como el germen de un futuro cluster que se puede materializar a corto plazo. Ciertamente han aparecido vínculos comerciales, organizativos y funcionales entre determinados sectores de la cadena de valor de la actividad, como los que le aportan recursos para su desarrollo (turismo, agroalimentación, artesanía) y los que favorecen su inserción en la sociedad (sectores institucionales, cívicos, comunitarios, participativos). Pero habrá que superar diversos handicaps, entre los cuales pueden citarse el tamaño de la ciudad, la concentración de la demanda en un período breve, y su capacidad limitada para general mayor impacto. Así mismo debería mejorar la reducida dimensión de las empresas y su debil relación entre ellas y con las instituciones, que, a su vez, deberían reforzar más su implicación. Además, es necesaria una mayor difusión de esta recreación festiva, para lo que conviene establecer relaciones con otras partes de España y de otras áreas de Europa y, a partir de ahí, configurar inicitivas turísticas que incluyan esta fiesta.

Cabe insitir, por último, en que las organizaciones que gestionan la celebración pongan especial cuidado en no perder algunos de los rasgos que han permitido su éxito. Es una iniciativa popular, participativa y transparente, inclusiva en términos sociales y buen ejemplo de las dinámicas del desarrollo endógeno. Por ello la consolidación de ciertas funciones y actividades debe ir acompañada de la renovación en los diferentes cargos y responsabilidades. En todo caso, el papel de las actividades creativas como base de un cluster de estas características, es intrínsecamente interesante como un ejemplo de fomento del desarrollo local.

\section{REFERENCIAS BIBLIOGRÁFICAS}

BAKHSHI, H.; FREEMAN, A. y HIGGS, P. (2013): "A dynamic mapping of the UK's creative industries". Londres, NESTA (National Endowment for Science, Technology and the Arts)

BATHELT, H., MALMBERG, A. y MASKELL, P. (2004): "Clusters and knowledge: local buzz, global pipelines and the process of kowledge creation", en Progress in Human Geography, 28 (1), pp. 31-56.

CAMAGNI, R. (2003): "Uncertainty, social capital and local development: lessons for a sustainable governability of the territory", en Investigaciones Regionales, 2, pp. 31-57.

CINTI, T. (2008): "Cultural clusters and districts. The state of the Art", en COOKE, Ph. y LAZZERETTI, L., Creative cities, Cutural Clusters and Local Economic Development, Elgar, pp. 70-92.

COMISIÓN EUROPEA (2012): "How can cultural and creative industries contribute to economic transformation through smart specialization". Bruselas

ESCALONA-ORCAO, A.I.; SÁEZ-PÉREZ, L.A.; SÁNCHEZ-VALVERDE, B.; ESCOLANO UTRILLA, S.; LOSCERTALES-PALOMAR, B. y FRUTOS MEJÍAS, L.M. (en prensa), "A pathway for local development. The clusters of creative industries in small cities and rural areas of Spain", en Semestrale di Studi e Ricerche di Geografia.

HOGGART, K. y PANIAGUA, A. (2001): "What rural restructuring?", en Journal of Rural Studies, 17/1, pp. 41-62.

LAFFONT, J.J. (2008): "Externalities", "The New Palgrave Dictionary of Economics", en Steven N. Durlauf y Lawrence E. Blume, Palgrave Macmillan (eds.) The New Palgrave Dictionary of Economics Online, Palgrave Macmillan. <http://www.dictionaryofeconomics.com/article?id=pde2008 E000200>, 10 de marzo de 2014.

LAZERETTI, L., BOIX, R., y CAPONE, F. (2008): "Do Creative Industries Cluster? Mapping Creative Local Production Systems in Italy and Spain", en Industry \& Innovation, 15 (5), pp. 549-567.

LUNDMARK, L. y PETTERSSON, O. (2012): "The Relevance of Cluster Initiatives in Rural Areas: Regional Policy in Sweden", en Urbani izziv, 23 (1), pp. 42-52.

McGRANAHAN, D. y WOJAN, T. (2007): "The creative class. A key to rural growth", en Amber Waves, 5(2), pp. 16-21.

MÉNDEZ, R.; MICHELINI, J. J.; PRADA, J. y TÉBAR, J. (2012): "Economía creativa y desarrollo urbano en España: Una aproximación a sus lógicas espaciales", en EURE, 38(113), pp. 5-32.

PORTER, M.E. (1998): "Clusters and the new economics of competition", en Harvard Business Review, 76, pp. $77-90$.

RODRÍGUEZ-POSE, A. y COMPTOUR, F. (2012): "Do clusters generate greater innovation and growth? An analysis of european regions", en The Professional Geographer, 64(2), pp. 211-231. 
SÁNCHEZ MORAL S., MÉNDEZ, R. y ARELLANO, A. (2014): "Creative economy and employment quality in large urban areas in Spain", en Urban Geography (DOI:10.1080/02723638.2013.876145)

SHIFFERD, P. (2005): "The arts in small communities: Report of a study of ten Minnesota towns", Saint Paul, Minesota, Metropolitan Regional Arts Council.

STORPER, M. y VENABLES, A.J. (2003): "Buzz: Face to face contact and the urban economy". Londres, Centro para el Desarrollo económico, servicio de publicaciones.

UNITED NATIONS (2010): "Creative economy Report, 2010. Creative economy: A feasible development option". Nueva York. 